\title{
Analyst
}

CORRECTION

View Article Online

View Journal I View Issue

\section{Correction: Continuous and simultaneous measurement of the biophysical properties of blood in a microfluidic environment}

Cite this: Analyst, 2017, 142, 397

Yang Jun Kang

DOI: 10.1039/c6an90102f

Correction for 'Continuous and simultaneous measurement of the biophysical properties of blood in a

www.rsc.org/analyst

microfluidic environment' by Yang Jun Kang, Analyst, 2016, 141, 6583-6597.

In the original manuscript the expression for the correction factor $F_{\mu}$ was given incorrectly, as

$$
F_{\mu}=0.16 \alpha_{\mathrm{x}}{ }^{5}+8.357 \alpha_{\mathrm{x}}{ }^{4}-35.554 \alpha_{\mathrm{x}}{ }^{3}+74.753 \alpha_{\mathrm{x}}{ }^{2}-76.023 \alpha_{\mathrm{x}}+30.096
$$

in two places:

- p. 6588 , line 9 of the caption to Fig. 3 ; and

- p. 6590, right column, lines 12 and 13 up from the bottom of the page.

In each case, the correct formula for correction factor $F_{\mu}$ should be as follows:

$$
F_{\mu}=30.096 \alpha_{\mathrm{x}}{ }^{5}-76.023 \alpha_{\mathrm{x}}{ }^{4}+74.753 \alpha_{\mathrm{x}}{ }^{3}-35.554 \alpha_{\mathrm{x}}{ }^{2}+8.357 \alpha_{\mathrm{x}}+0.16
$$

The Royal Society of Chemistry apologises for these errors and any consequent inconvenience to authors and readers. 